\title{
Estimating elastic impedance from seismic inversion method: a study from Nova Scotia field, Canada
}

\author{
S. P. Maurya* \\ Department of Geophysics, Institute of Science, Banaras Hindu University, Varanasi 221005 , India
}

In the present study, elastic impedance (EI) inversion is performed to estimate subsurface elastic properties in inter-well regions. These elastic properties are helpful to discriminate gas-bearing formation from gasfree formation, as well as overpressure zone. Seismic reflection data from the Penobscot Scotia shelf, Canada are used for the analysis which is performed in two steps. First, the method is tested with noise-free synthetic data, as well as with addition of $5 \%, 10 \%, 20 \%$ and $30 \%$ Gaussian noise. The analysis shows that efficacy of EI inversion decreases by $3.4 \%$ with addition of $30 \%$ noise in the data compared to noise-free data. In the second step, EI inversion is applied to the real data and variation of $E I$ is estimated for near- and far-angle stack gathers. The analysis demonstrates that the inverted results follow the well-log curve satisfactorily. The results also show higher resolution images for the far-stack data compared to the nearstack data. Incidentally, it is noticed that the area of study does not contain any major gas or overpressure zones. As of now, the analysis has been performed for small datasets of the region. Robustness of the method needs to be tested with more data from other parts of the region as well.

Keywords: Elastic impedance, gas formation, modelbased inversion, overpressure zone.

SEISMIC inversion techniques have been routinely used to map subsurface structures both in the field of seismology and seismic exploration. In the latter, inversion helps extract the underlying model of physical characteristics of rocks and fluids that are helpful for reservoir characterization ${ }^{1}$. The present work involves extracting elastic impedance (EI) variation in inter-well regions from seismic reflection data. Usually, inversion depends on some form of forward modelling that generates the earth's response from a set of model parameters. The inversion then aspires to generate a best-fitting model that satisfies the observed dataset following some form of minimization procedure $^{2-6}$.

The seismic inversion techniques can be divided into two broad categories: post-stack and pre-stack inversions.

\footnotetext{
*e-mail: spm.bhu@gmail.com
}

The first approach is most commonly used, in which the effect of the wavelet is removed from seismic data and a high-resolution image of the subsurface is generated ${ }^{7}$. The second approach relies on model-building from well$\log$, seismic and geological data ${ }^{8,9}$. This also generates high-resolution image of the subsurface from which reservoir properties are estimated. A reliable estimate of the reservoir properties is critical in decision-making process during development phase $\mathrm{e}^{4,10}$.

Elastic impedance inversion is a generalization of acoustic impedance inversion that uses pre-stack seismic reflection data as input ${ }^{11}$. The output of elastic impedance is useful to interpret gas-filled formations ${ }^{12-16}$. There are many approaches available for EI inversion, i.e. full prestack inversion, post-stack inversion using amplitude variation with offset (AVO; termed 'AVO inversion'), and post-stack inversion using elastic impedance (termed 'EI inversion'). In the present study, post-stack inversion using elastic impedance is chosen for analysis, because the method is fast and easy for real-data applications. Although computationally expensive, full pre-stack inversion is the optimum approach to obtain elastic parameters from seismic reflection data. However, good results have also been obtained using AVO inversion ${ }^{17}$ and EI inversion ${ }^{14}$.

In the present study, elastic impedance inversion is employed to seismic reflection data from the Penobscot field, Nova Scotia, Canada for estimating the elastic rock properties. Analysis has been performed in two steps: first a synthetic seismogram is generated over seven layer earth models and elastic inversion is performed to estimate the elastic property. Thereafter, 5\%, 10\%, 20\% and $30 \%$ random noise is added to the synthetic data and elastic inversion is performed to estimate the effect of noise. In the second step, the elastic inversion method is applied to real data and elastic rock properties are estimated for near-stack, as well as far-stack seismic data, and the results are compared.

\section{Study area}

The Penobscot field is located in the Scotian shelf, offshore Nova Scotia, Canada (Figure 1). The area contains many structural and stratigraphic features in the subsurface. 
Many minor, but two major faults can be inferred from the seismic data ${ }^{18}$. The major faults displace the interpreted seismic horizons ${ }^{19}$. The data are recorded over an area of $7.2 \mathrm{~km} \times 12.03 \mathrm{~km}$. The seismic sections have 1000 to 1600 inlines and 1000 to 1481 crosslines, and the section goes up to $6000 \mathrm{~ms}$ (millisecond) depth. The measured seismic signal is poor below $3000 \mathrm{~ms}$. Apart from this, well logs for L-30 and B-41 boreholes in the area yield caliper $\log$, gamma-ray $\log$, resistivity $\log$, sonic $\log$, SP $\log$, etc. ${ }^{20}$. Several minor oil and gas fields are located in these Late Jurassic to Cretaceous formations, but they are difficult to interpret from seismic reflection data. The seismic reflection data are divided into $15 \mathrm{com}-$ ponents, where one component contains 40 in-line and all crosslines. Seismic data from inline 1161 to inline 1200 and crossline 1000 to crossline 1481 along with well L30 are utilized for the analysis. The seismic and well data have been downloaded from the Opend Tect seismic data portal. The time-to-depth models have been taken from the Canada-Nova Scotia Offshore Petroleum Board report (unpublished). The survey contains a limited range of pre-stack data. The data cover many geological features, which include graben-bounding faults, channels, megascale de-watering faults and reefs ${ }^{21}$.

\section{Theory}

EI is generalization of the acoustic impedance of offsetdependent angle gather seismic data. Because $P / S$ mode conversions are significant at oblique incidence angle, EI inversion gives a more detailed picture of the subsurface $^{11,22}$. EI inversion can be done from the small-contrast Aki and Richards equation (eq. (1)). Connolly ${ }^{11}$ was the first to use range-limited stack sections to invert elastic impedance. The reflection coefficient $R(\theta)$ can be calcu-

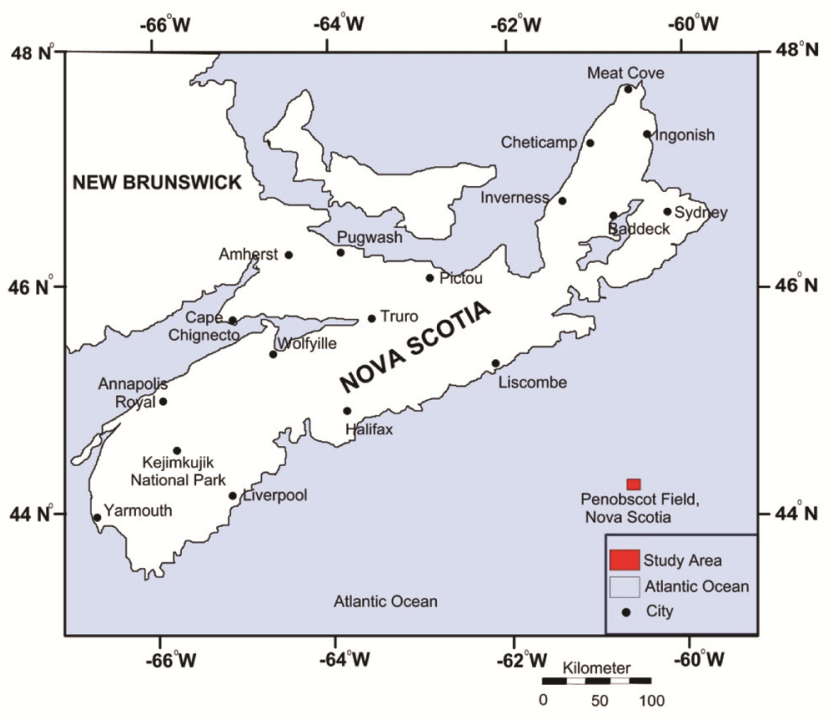

Figure 1. Location of Penobscot field, Canada. lated using Zeopritz equation for $P$-wave reflectivity for an angle $\theta$ as

$$
R(\theta)=A+B \sin ^{2} \theta+C \sin ^{2} \theta \tan ^{2} \theta,
$$

where

$$
\begin{gathered}
A=\frac{1}{2}\left(\frac{\Delta V_{P}}{\bar{V}_{P}}\right), B=\frac{\Delta V_{P}}{\bar{V}_{P}}-4 \frac{V_{S}^{2}}{V_{P}^{2}} \frac{\Delta V_{S}}{\bar{V}_{S}}-2 \frac{V_{S}^{2}}{V_{P}^{2}} \frac{\Delta \rho}{\bar{\rho}} \text { and } \\
C=\frac{1}{2} \frac{\Delta V_{P}}{\bar{V}_{P}},
\end{gathered}
$$

and

$$
\begin{aligned}
& \bar{V}_{P}=\frac{V_{P}\left(t_{i}\right)+V_{P}\left(t_{i-1}\right)}{2}, \Delta V_{P}=V_{P}\left(t_{i}\right)+V_{P}\left(t_{i-1}\right), \\
& \frac{V_{S}^{2}}{V_{P}^{2}}=\left(\frac{V_{S}^{2}\left(t_{i}\right)}{V_{P}^{2}\left(t_{i}\right)}-\frac{V_{S}^{2}\left(t_{i-1}\right)}{V_{P}^{2}\left(t_{i-1}\right)}\right) / 2,
\end{aligned}
$$

and similarly for the other variables where $V_{P}$ is the $P$-wave velocity, $V_{S}$ the $S$-wave velocity, $\rho$ the density and $t_{i}$ is the time at sample $i$.

Further, one requires a function $f(t)$ which has properties analogous to acoustic impedance, such that reflectivity can be derived from eq. (2) for any incidence angle $\theta$

$$
R(\theta)=\frac{f\left(t_{i}\right)-f\left(t_{i-1}\right)}{f\left(t_{i}\right)+f\left(t_{i-1}\right)} .
$$

Equation (2) is used to estimate elastic impedance. This equation can also be written as follows for small to moderate angle of incidence

$$
R(\theta) \approx \frac{1}{2} \frac{\Delta \mathrm{EI}}{\mathrm{EI}} \approx \frac{1}{2} \Delta \ln (\mathrm{EI})
$$

Thus, eq. (1) can be rewritten as

$$
\begin{aligned}
\frac{1}{2} \Delta \ln (\mathrm{EI})= & \frac{1}{2}\left(\frac{\Delta V_{P}}{\bar{V}_{P}}+\frac{\Delta \rho}{\bar{\rho}}\right)+\left(\frac{\Delta V_{P}}{2 \bar{V}_{P}}-4 \frac{V_{S}^{2}}{V_{P}^{2}} \frac{\Delta V_{S}}{\bar{V}_{S}}-2 \frac{V_{S}^{2}}{V_{P}^{2}} \frac{\Delta \rho}{\bar{\rho}}\right) \\
& \times \sin ^{2} \theta+\frac{1}{2} \frac{\Delta V_{P}}{\bar{V}_{P}} \sin ^{2} \theta \tan ^{2} \theta
\end{aligned}
$$

If $K=\left(V_{S}^{2} / V_{P}^{2}\right)$, then eq. (4) can be written as

$$
\begin{aligned}
\frac{\Delta V_{P}}{2 \bar{V}_{P}}+ & \frac{\Delta \rho}{2 \bar{\rho}}+\frac{\Delta V_{P}}{2 \bar{V}_{P}} \sin ^{2} \theta-4 K \sin ^{2} \theta \frac{\Delta V_{S}}{\bar{V}_{S}} \\
& -2 K \frac{\Delta \rho}{\bar{\rho}} \sin ^{2} \theta+\frac{1}{2} \frac{\Delta V_{P}}{\bar{V}_{P}} \sin ^{2} \theta \tan ^{2} \theta .
\end{aligned}
$$


Rearranging the terms we get

$$
\begin{aligned}
\frac{1}{2}\left[\frac{\Delta V_{P}}{\bar{V}_{P}}(1\right. & \left.+\sin ^{2} \theta\right)+\frac{\Delta \rho}{\bar{\rho}}\left(1-4 K \sin ^{2} \theta\right) \\
& \left.-\frac{\Delta V_{S}}{\bar{V}_{S}} 8 K \sin ^{2} \theta+\frac{\Delta V_{P}}{\bar{V}_{P}} \sin ^{2} \theta \tan ^{2} \theta\right]
\end{aligned}
$$

Using $\sin ^{2} \theta \tan ^{2} \theta=\tan ^{2} \theta-\sin ^{2} \theta$, eq. (6) becomes

$$
\frac{1}{2}\left[\frac{\Delta V_{P}}{\bar{V}_{P}}\left(1+\tan ^{2} \theta\right)-\frac{\Delta V_{S}}{\bar{V}_{S}} 8 K \sin ^{2} \theta+\frac{\Delta \rho}{\bar{\rho}}\left(1-4 K \sin ^{2} \theta\right)\right] .
$$

We have used only the first two terms of eq. (1). Then the above (eq. (6) and (eq. (7)) and following expressions differ only by changing $\tan ^{2} \theta$ to $\sin ^{2} \theta$. We substitute again $\Delta \ln x$ for $\Delta x / x$

$$
\begin{aligned}
\Delta \ln (\mathrm{EI})=(1 & \left.+\tan ^{2} \theta\right) \Delta \ln \left(V_{P}\right)-8 K \sin ^{2} \theta \Delta \ln \left(V_{S}\right) \\
& +\left(1-4 K \sin ^{2} \theta\right) \Delta \ln (\rho) .
\end{aligned}
$$

Now, if we make $K$ a constant, we can take all terms inside $\Delta s$

$$
\begin{aligned}
\Delta \ln (\mathrm{EI})= & \Delta \ln \left(V_{P}^{\left(1+\tan ^{2} \theta\right)}\right)-\Delta \ln \left(V_{S}^{\left(8 K \sin ^{2} \theta\right)}\right) \\
& +\Delta \ln \left(\rho^{\left(1-8 K \sin ^{2} \theta\right)}\right)
\end{aligned}
$$

$$
\Delta \ln (\mathrm{EI})=\Delta \ln \left(V_{P}^{\left(1+\tan ^{2} \theta\right)} V_{S}^{\left(8 K \sin ^{2} \theta\right)} \rho^{\left(1-8 K \sin ^{2} \theta\right)}\right) .
$$

Finally we integrate and exponentiate (i.e. remove the differential and logarithmic terms on both sides), setting the integration constant to zero

$$
\mathrm{EI}=V_{P}^{\left(1+\tan ^{2} \theta\right)} V_{S}^{\left(8 K \sin ^{2} \theta\right)} \rho^{\left(1-8 K \sin ^{2} \theta\right)} .
$$

Equation (11) is the final output which is used to estimate elastic impedance provided $P$-wave velocity, $S$-wave velocity, density and angle $\theta$ are known ${ }^{11,22,23}$.

\section{Results and discussion}

\section{Synthetic data example}

Figure 2 depicts inversion results estimated using elastic inversion method for noise-free as well as noisy data. Figure $2 a, c, e, f$ and $i$ displays synthetic seismograms, and Figure $2 b, d, f, h$ and $j$ displays inversion results for noise-free data as well as data with $5 \%, 10 \%, 20 \%$ and
$30 \%$ noise respectively. The analysis shows that the inverted impedance curve follows the original impedance well. It is also noticed that the inverted curves deviate from the original curve for Gaussian noise $>10 \%$. The correlation is estimated to be $0.999,0.998,0.995,0.983$ and 0.965 and error varies as $0.017,0.048,0.089,0.186$ and 0.262 for noise-free, $5 \%, 10 \%, 20 \%$ and $30 \%$ noise in the data respectively. The efficacy of the EI method is estimated and found to decrease by $3.4 \%$ with addition of up to $30 \%$ noise in the data compared with noise-free data.

Figure 3 shows variation of RMS error and variation of correlation with addition of Gaussian noise in the data. The analysis shows that RMS error increases with increase in Gaussian noise in the data, while correlation decreases. It is also noticed that RMS error increases sharply up to $5 \%$ noise, then increases smoothly up to $20 \%$ noise and thereafter increases sharply again.

\section{Real data example}

Real data from the Penobscot field is utilized to estimate subsurface elastic properties using elastic impedance inversion technique. Pre-stack seismic data from inlines 1161 to 1200 and crosslines 1001 to 1481 along with well L-30 are used for the analysis. Initially data preparation was done by partial stacking, horizon picking, conversion of depth to time, wavelet extraction and generation of low-frequency initial model. Figure 4 shows near-angle stack (left) and far-angle stack (right) which are used as inputs for elastic impedance inversion method. The figure depicts that the signal-to-noise ratio increases due to stacking, which is usual case; but it can also be observed that the resolution of far stack section increases more than that of the near stack gather (highlighted by arrows). The near stack represents stacking of 0-15 degree traces while the far angle stack represents stacking of 16-30 degree traces. After preparing the data, elastic impedance inversion is applied to the data in two steps: First, a composite trace in the vicinity of the well location is extracted from near- and far-angle stack gather and inversion is performed; the results are compared with well log data.

Figure 5 shows a comparison of inverted elastic impedance from near stack as well as far stack with well log impedance. It can be noticed from the figure that the inverted EIs for the near stack and far stack agree satisfactorily with the well log EI. The estimated correlation is very high (0.94) and error is 0.13 , which indicates good performance of the algorithm. For quality check, crossplot is generated between original and inverted elastic impedance for near- (left, Figure 6) as well as far-angle stack (right, Figure 6) data. It can be noticed from Figure 6 that the maximum scatter points lie close to the best-fit 

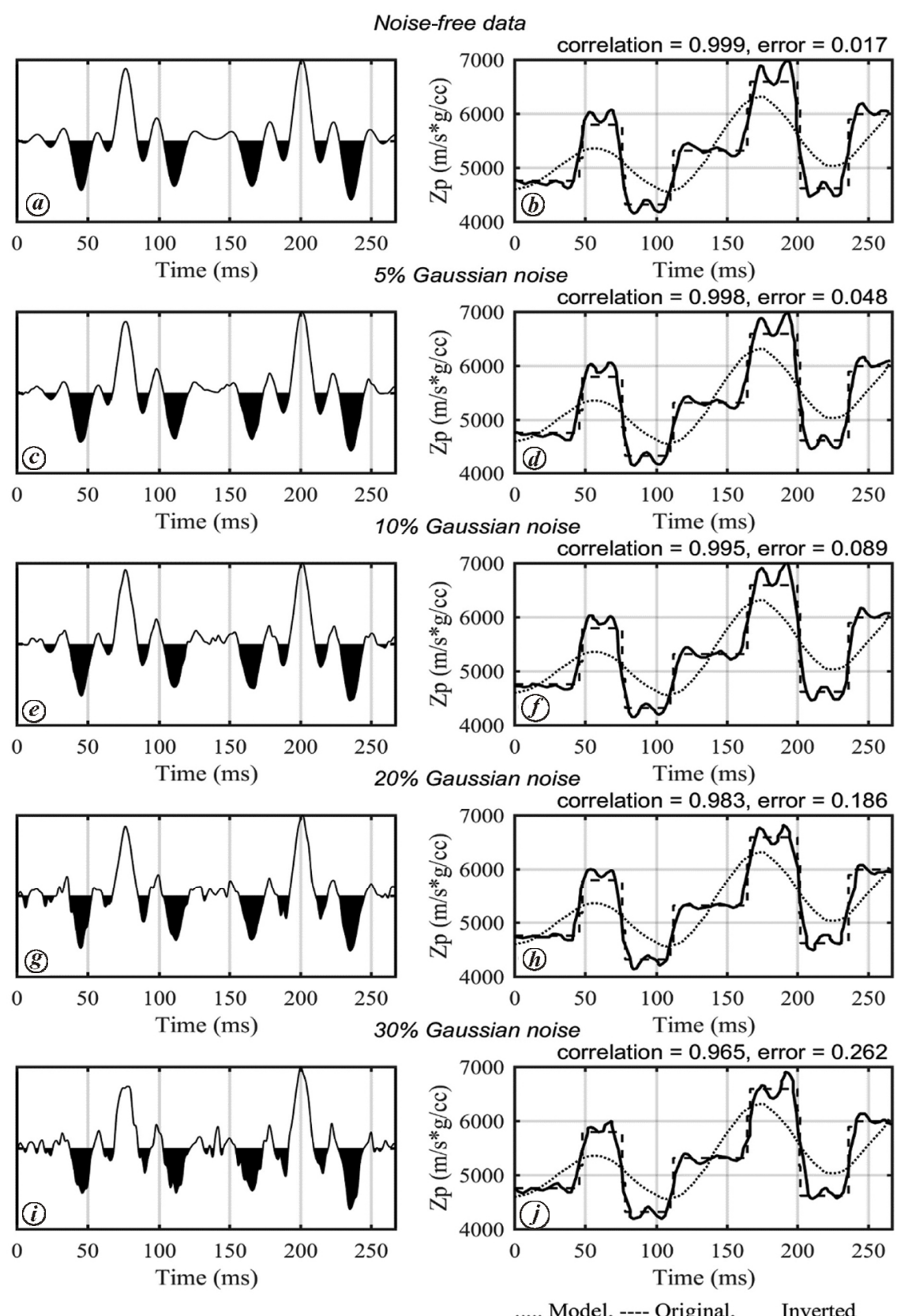

Figure 2. Elastic impedance inversion results for synthetic case. (Left) Seismograms and (right) the corresponding inversion results.
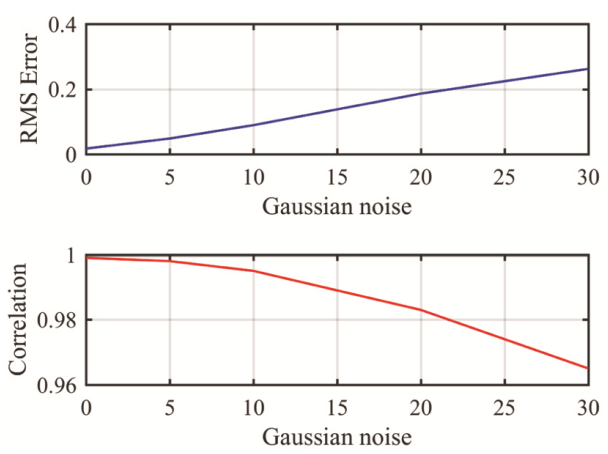

Figure 3. (Top) Variation of RMS error and (bottom) variation of correlation coefficient with Gaussian noise for post-stack seismic inversion techniques. line for both cases (near- and far-angle stack), indicating good performance of the algorithm.

EI is an extension of acoustic impedance (AI), and Figure 7 shows a comparison of the EI curve from nearand far-angle stack seismic sections and the AI curve. From the figure, one can notice that the EI curve closely follows the trend of the AI curve, which indicates good results. A cross-plot of near-stack elastic impedance with far-stack elastic impedance is generated with colour bar of acoustic impedance (Figure 8). It can be seen from Figure 8 that the EIs of near- and far-angle stacks vary in a similar manner. In the presence of gas zone, some cluster points away from the best-fit line would appear, which is not seen in Figure 8. Therefore, possibility of occurrence 


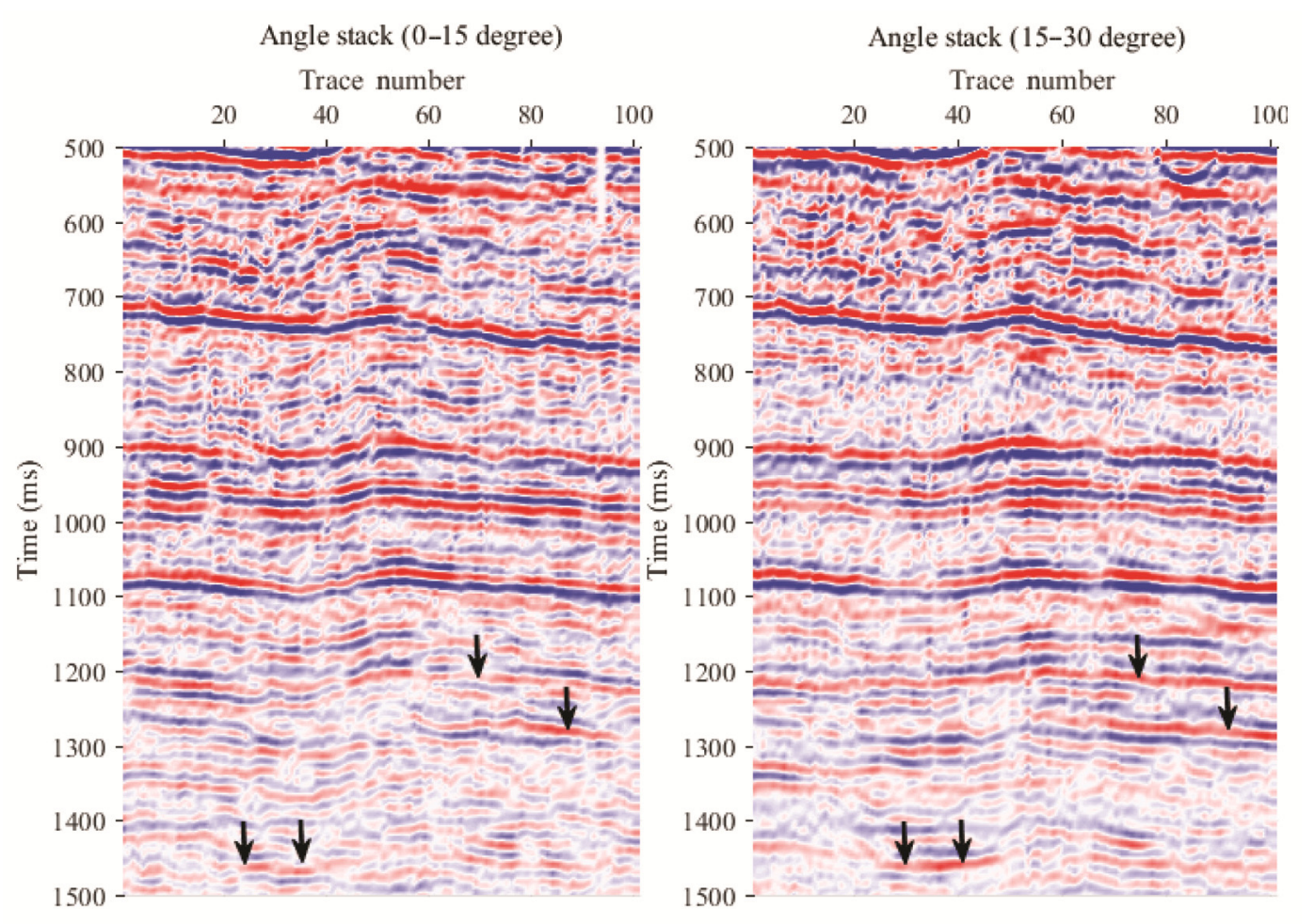

Figure 4. (Left) Near-angle stack and (right) far-angle stack sections; major difference between them is highlighted.

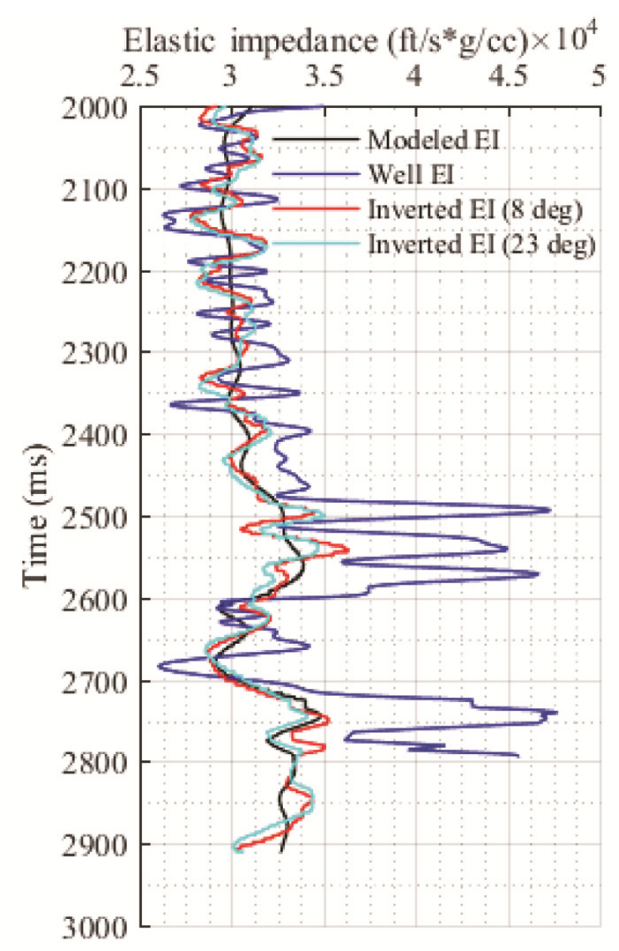

Figure 5. Comparison of inverted and original elastic impedance (EI) for composite trace case.

of gas-bearing formation is low in the study area. However, it must be mentioned that this is a preliminary inter- pretation of composite traces. It does not rule out the chance of occurrence of gas-bearing formation(s) in areas away from the present location.

In the second step, the entire seismic section is inverted for elastic impedance and Figure 9 shows the crosssection. The left side of the figure shows elastic impedance for near-angle stacks, while the right-side for farangle stacks. The differences between near- and far-angle stack elastic impedance sections are highlighted by arrows. The improved reflector resolution is high in farstack elastic impedance section compared to near-stack section. As shown in Figure 10, a cross-plot of near-stack and far-stack elastic impedance is generated for the entire dataset. The scatter points lie very close to the best-fit line. There is no cluster of points anywhere in the cross plot, which indicates that, the area does not contain any major gas formation. However, the presence of gas formation elsewhere, which could be minor, is not detectable by elastic impedance inversion method. Analyses are performed for seismic data for the area containing inlines 1161 to 1200 and crosslines 1001 to 1481 . On the basis of this, occurrence of gas formation outside the zone of study cannot be ruled out.

\section{Conclusion}

In the present study elastic impedance inversion method is utilized to estimate subsurface elastic properties which 

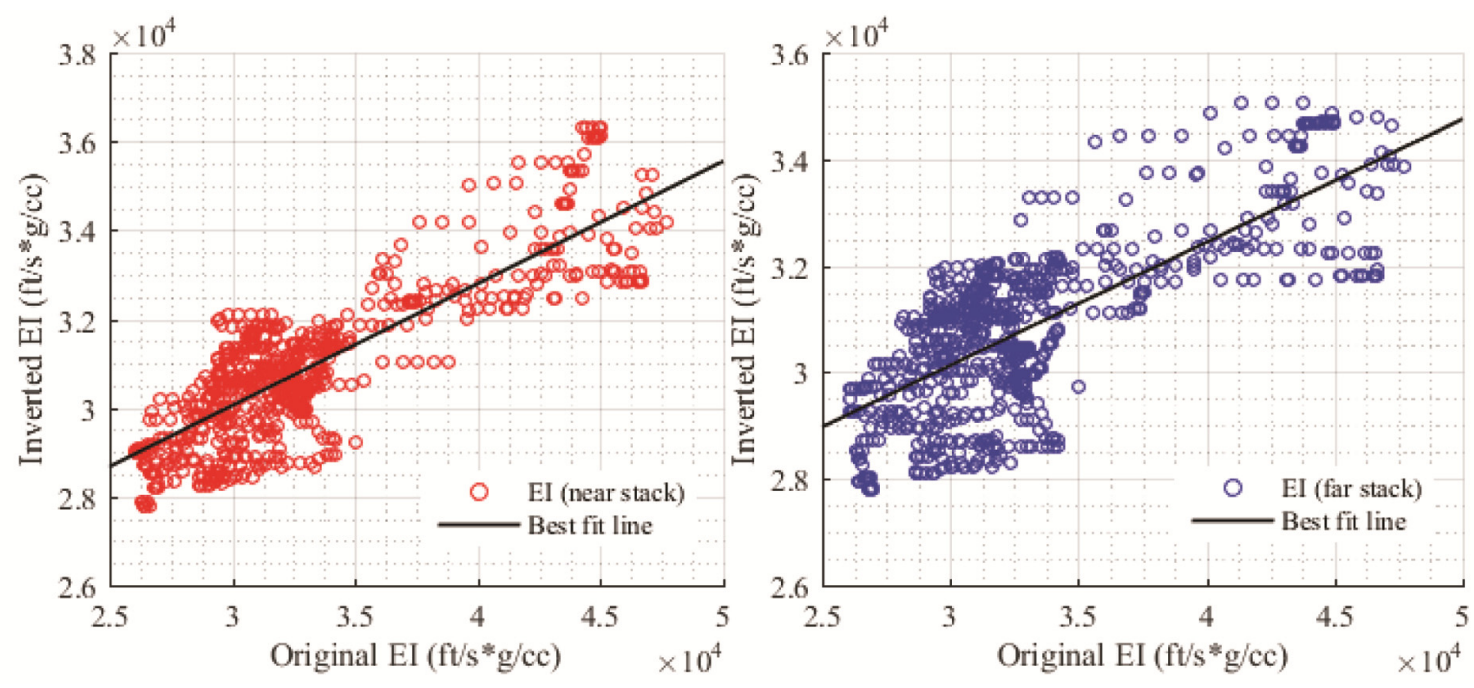

Figure 6. Cross-plot of inverted and original elastic impedance for (left) near-angle stack and (right) far-angle stack.

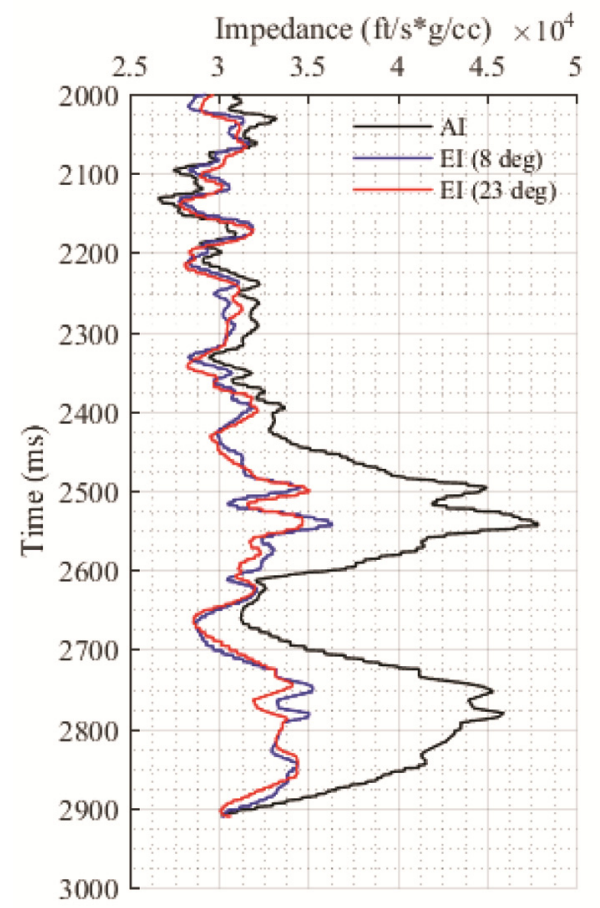

Figure 7. Comparison of elastic impedance with acoustic impedance for composite trace near a well location.

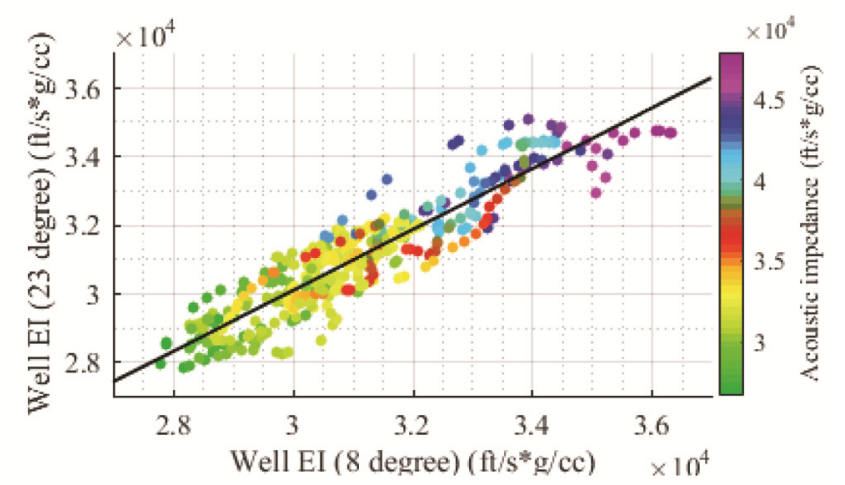

Figure 8. Cross-plot of well log elastic impedance from near-offset versus far-offset data. The colour bar shows acoustic impedance from well log. 


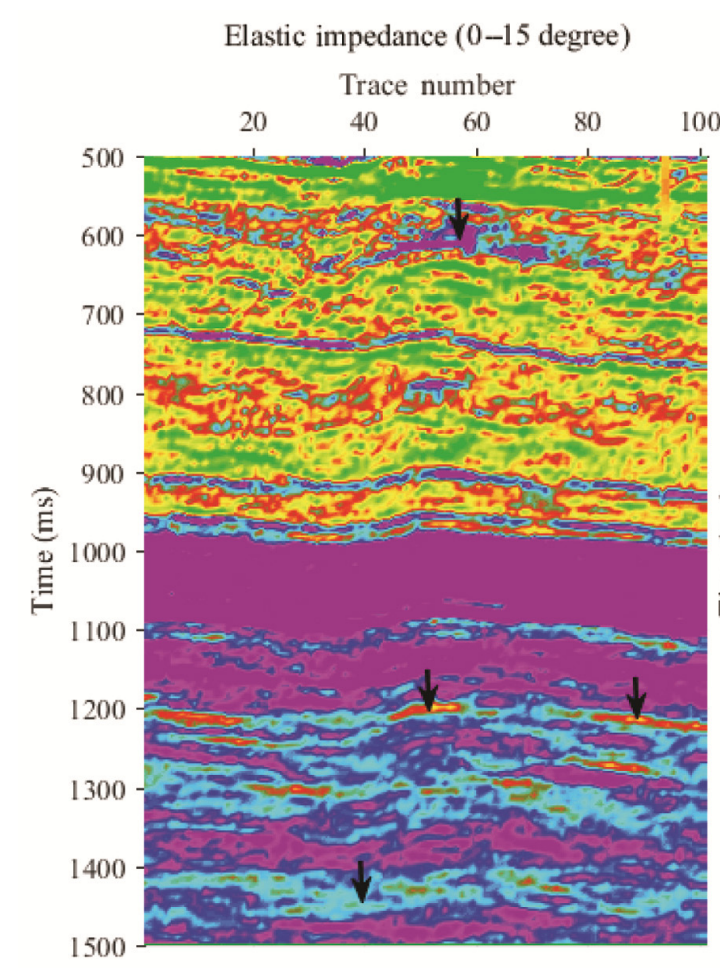

Elastic impedance (15-30 degree)

Trace number

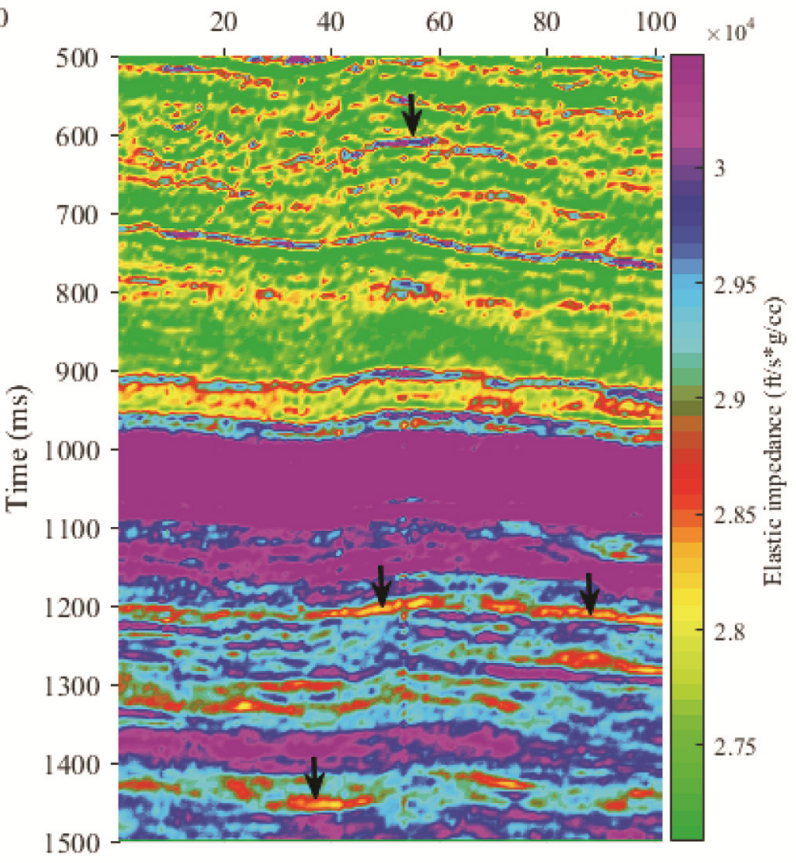

Figure 9. Cross-section of inverted elastic impedance generated for (left) near-stack angle gather and (right) far-stack angle gather. The differences between the two are highlighted by arrows.

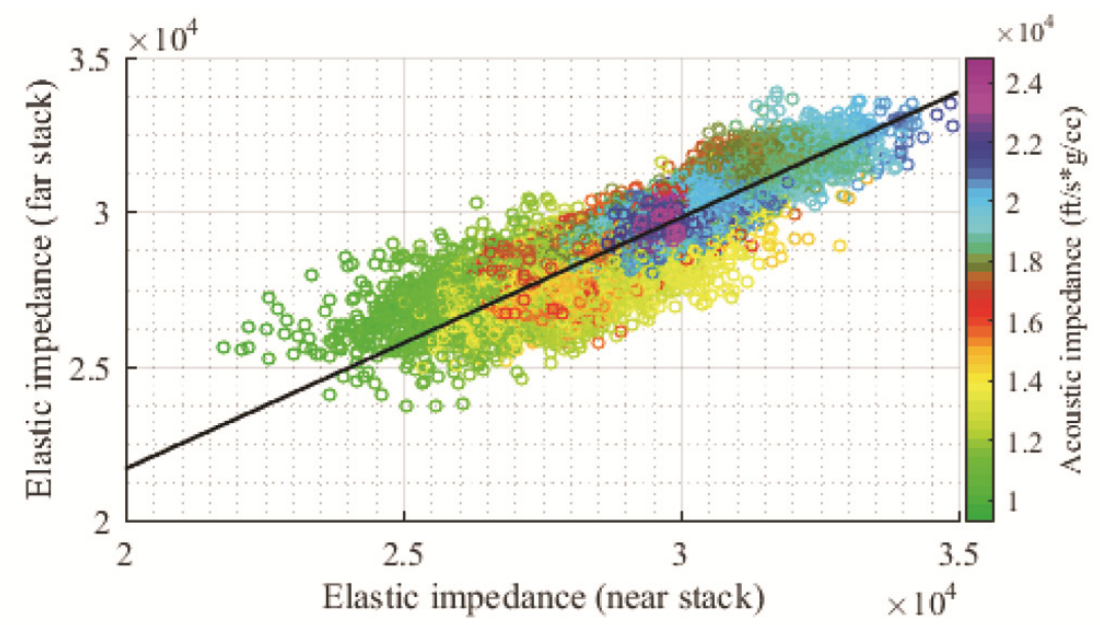

Figure 10. Cross-plot of inverted elastic impedance from near-stack seismic section versus far-stack seismic section. The colour bar shows inverted acoustic impedance.

give high-resolution subsurface information. These properties are helpful to discriminate hydrocarbon-bearing formation filled with gas from non-gas-bearing formation. The method uses behaviour of $P$ - and $S$-wave velocities in gas-filled formations to discriminate them. The elastic impedance inversion does not show much deviation for noises up to $10 \%$ level, and after that small deviation can be noticed. The performance of EI decreases by $3.4 \%$ after adding $30 \%$ Gaussian noise in the data. Further, the analysis for composite trace near the well location demonstrates good performance of the algorithm, as the inverted curves follow the trend of the original curve satisfactorily. The inverted volume from the far-stack seismic section shows higher resolution compared to the near-stack seismic section. It is also concluded that part of the Penobscot area of Canada studied does not contain any major gas formations. These analyses are performed for small datasets of the region, and so conclusions need further verification in other parts of the study area as well. 
1. Maurya, S. P. and Sarkar, P., Comparison of post stacks seismic inversion methods: a case study from Blackfoot Field, Canada. IJSER, 2016, 7(8), 1091-1101.

2. Maurya, S. P. and Singh, K. H., LP and ML sparse spike inversion to characterize reservoir: a case study. In 77th EAGE Conference and Exhibition, Madrid, Spain, 2015; doi:10.3997/2214-4609. 201412822.

3. Maurya, S. P. and Singh, K. H., Band limited impedance inversion of Blackfoot field, Alberta, Canada. J. Geophys., 2017, 38(1), 57-61.

4. Maurya, S. P., Singh, K. H. and Singh, N. P., Qualitative and quantitative comparison of geostatistical techniques of porosity prediction from the seismic and logging data: a case study from the Blackfoot Field, Alberta, Canada. Mar. Geophys. Res., 2018, pp. 1-21; http://doi.org/10.1007/s11001-018-9355-6.

5. Russell, B. and Hampson, D., Comparison of poststack seismic inversion methods. In SEG Technical Program Expanded Abstracts, Society of Exploration Geophysicists, Houston, Texas, 1991, pp. 876-878.

6. Russell, B. H., Introduction to Seismic Inversion Methods, Society of Exploration Geophysicists, Tulsa, OK, 1988, p. 90.

7. Chen, Q. and Sidney, S., Seismic attribute technology for reservoir forecasting and monitoring. Leading Edge, 1997, 16(5), 445-448.

8. Chopra, S. and Marfurt, K. J., Seismic attributes - a historical perspective. Geophysics, 2005, 70(5), 3SO-28SO.

9. Downton, J. E., Seismic parameter estimation from AVO inversion. Department of Geology and Geophysics, University of Calgary, Canada, 2005, pp. 3605-3605.

10. Pendrel, J., Seismic inversion - a critical tool in reservoir characterization. Scand. Oil-Gas Mag., 2006, 5(6), 19-22.

11. Connolly, P., Elastic impedance. Leading Edge, 1999, 18(4), 438452 .

12. Jin, Y. K., Lee, M. W., Kim, Y., Nam, S. H. and Kim, K. J., Gas hydrate volume estimations on the South Shetland continental margin, Antarctic Peninsula. Antarct. Sci., 2003, 15(2), 271-282.

13. Lu, S. and McMechan, G. A., Estimation of gas hydrate and free gas saturation, concentration, and distribution from seismic data. Geophysics, 2002, 67(2), 582-593.

14. Lu, Shaoming and McMechan, G. A., Elastic impedance inversion of multichannel seismic data from unconsolidated sediments containing gas hydrate and free gas. Geophysics, 2004, 69, 164-179.
15. Mallick, S., Huang, X., Lauve, J. and Ahmad, R., Hybrid seismic inversion - a reconnaissance tool for deepwater exploration. Leading Edge, 2000, 19, 1230-1251.

16. Sakai, A., Velocity analysis of vertical seismic profile (VSP) survey at JAPEX/JNOC/GSC Mallik 2L-38 gas hydrate research well, and related problems for estimating gas hydrate concentration. GSC Bull., 1999, 544, 323-340.

17. Mallick, S., AVO and elastic impedance. Leading Edge, 2011, 20, 1094-1104.

18. Campbell, D. C., Shimeld, J., Deptuck, M. E. and Mosher, D. C., Seismic stratigraphic framework and depositional history of a large Upper Cretaceous and Cenozoic depocenter of Southwest Nova Scotia, Canada. Mar. Pet. Geol., 2015, 65, 22-42.

19. Cummings, D. I. and Arnott, R. W. C., Growth-faulted shelfmargin deltas: a new (but old) play type, offshore Nova Scotia. Bull. Can. Pet. Geol., 2005, 53(3), 211-236.

20. Kidston, A. G., Brown, D. E., Smith, B. M. and Altheim, B., The Upper Jurassic Abenaki Formation offshore Nova Scotia: a seismic and geologic perspective. Canada-Nova Scotia Offshore Petroleum Board, Halifax, Nova Scotia, Canada, 2005, pp. 21-26.

21. Kidston, A. G., Brown, D. E. and Altheim, B., The Jurassic carbonate reef trend offshore Nova Scotia. In CM 2011-Abstracts, 4.

22. Whitcombe, D. N., Elastic impedance normalization. Geophysics, 2002, 67(1), 60-62.

23. Whitcombe, D. N., Connolly, P. A., Reagan, R. L. and Redshaw, T. C., Extended elastic impedance for fluid and lithology prediction. Geophysics, 2002, 67(1), 63-67.

ACKNOWLEDGEMENTS. I thank the Science and Engineering Research Board, Department of Science and Technology, New Delhi for financial support in form of a research project (grant no. PDF/2016/ 000888) under the National Post-doctoral Fellowship scheme. I also thank CGG Veritas, Mumbai for providing seismic and well log data of Blackfoot field, Alberta, Canada.

Received 9 August 2018; revised accepted 19 November 2018

doi: $10.18520 / \mathrm{cs} / \mathrm{v} 116 / \mathrm{i} 4 / 628-635$ 